\title{
Effects of novel bioorganic fertilizer application on soil enzymes and bacterial community in multi-site rice paddies in China
}

\author{
Zuren Li ${ }^{1,2}$, Jincai Han ${ }^{1}$, Haodong Bai ${ }^{1,2}$, Di Peng ${ }^{1}$, Lifeng Wang ${ }^{1}$ and Lianyang Bai ${ }^{1,2^{*}}$
}

\begin{abstract}
Application of a novel bioorganic fertilizer (BIO) has been effectively used to inhibit weeds in rice paddies. To identify changes in soil bacterial community and enzymes in response to BIO treatments, field experiments were carried out in five major rice-growing areas in China. The dominant phylogenetic groups recorded included Proteobacteria, Actinobacteria, Bacteroidetes, Firmicutes and Acidobacteria. Anaeromyxobacter, Bacteroides, Bifidobacterium, EscherichiaShigella, Geobacter and Haliangium were significantly different between BIO-treatment and untreated control and aided in general function (R), amino acid transport, metabolism (E) and transcription (K) clusters. The soil chemical properties and enzyme activities were less affected by BIO at these study sites. RDA analysis showed that soil bacterial community had a significant positive correlations among northern latitude, eastern longitude, exchangeable $\mathrm{K}$, total $\mathrm{K}$, total P, soil pH, and total N, except for organic matter, hydrolytic $\mathrm{N}$ and extractable P. Overall, our work showed that application of $\mathrm{BIO}$ does not alter the main community structure and functional diversity of soil bacteria in rice paddies and should be encouraged for use as a sustainable weed management strategy.
\end{abstract}

Keywords: Bioorganic fertilizer, Rice paddy, Weed management, Bacterial community, Soil enzyme

\section{Introduction}

Soils provide the physical anchor for crops and therefore the management of its quality is key, in order to maintain agricultural productivity and ecosystems sustainability (Bardgett 2010). Soil bacterial community and enzyme activities are important components for soil functioning. Soil bacterial communities are essential part of the microbial community, and play roles in soil habitats in terms of their biodiversity and biomass (Bahram et al. 2018). Microbial communities play specific roles in biogeochemical cycling and soil functioning through traits such as their species richness, biotic interactions and decomposing activities (Kumar et al. 2018). Soil enzyme activities are reliable parameters for monitoring both positive

\footnotetext{
*Correspondence: lybai196712@163.com

${ }^{1}$ Hunan Provincial Key Laboratory for Biology and Control of Weeds, Hunan Academy of Agricultural Sciences, Changsha 410125, China Full list of author information is available at the end of the article
}

and negative effects of agro-ecosystems on soil biological activity and crop productivity of agro-ecosystems (Stark et al. 2008). Data on soil enzyme activity include the direct or indirect expression of the soil physio-chemical properties, microorganism, above-ground plants, disturbance and evolution (Zhu et al. 2019). Both changes in soil bacterial community and enzyme activities can affect ecosystem stability in relation to environmental conditions. Thus, the assessment of the influence of biotic and abiotic stressors on the soil microbial community and enzyme activities has become a hot research area for the sustainability of agricultural ecosystem.

To protect rice against weeds, the application of synthetic herbicides is by far the most common management strategy followed. Evaluating the negative effects of herbicides on soil functions is critical for the sustainable utilization of soil and prevention of damage to agricultural ecosystems (Carvalho 2017). For instance, it was shown that treatment of soil with glyphosate at 
a rate of $360 \mathrm{~g}$ a.i. ha ${ }^{-1}$, had no significant effect on the soil enzymes (Cherni et al. 2015). Nguyen et al. (2018) showed that effects on soil enzymes were lower in lighttextured tenosol soil than vertosol and chromosol soils under glyphosate or Roundup CT application. Also, it was reported that the soil microbial structure of irrigated soils under herbicide (triasulfuron and prosulfocarb) treatment exhibited a higher proportion of Actinobacteria and lower relative amount of fungi than non-irrigated soils (Delgado et al. 2019). After bispyribac sodium (35 $\mathrm{g} \mathrm{ha}^{-1}$ and $70 \mathrm{~g} \mathrm{ha}^{-1}$ ) application, the soil microbial biomass carbon, dehydrogenase, alkaline phosphatase and urease activities were significantly decreased, and the heterotrophic bacteria, actinomycetes and fungal population also declined (Kumar et al. 2020). Therefore, the soil type and herbicide formulation are important factors that influence soil functions (Borowik et al. 2017).

Bioorganic fertilizers are mostly organic fertilizer obtained by secondary fermentation involving particular microorganisms (Ling et al. 2012). Bioorganic fertilizers improve soil vitality and organic matter content, and strengthen the effectiveness of pest biocontrol agents (Barakat and Al-Masri 2009). A novel bioorganic fertilizer developed by Wu et al. (2014) showed that it had the potential to inhibit bacterial wilt and suppress Ralstonia solanacearum growth. The early application of urea ammonium nitrate (UAN 28\%-N) at $112 \mathrm{~kg} / \mathrm{ha}$ was shown to increase the emergence rate of certain weeds such as Chenopodium album, Polygonum persicaria, Seteria faberi, and Abutilon theophrasti (Pearson et al. 2008). The application of pig manure reduced the effects of applying NPK complex fertilizers during the heading and ripening stages in rice, on paddy bacterial communities, but the effects of straw returning was not obvious (Wang et al. 2019a, b). Hence, bioorganic fertilizer is not only a fundamental soil quality resource, but also an effective carrier for the biocontrol of pests.

In our previous study, we developed a novel bioorganic weeding fertilizer (BIO) by fermenting mature compost with kitchen garbage, maize straw, wood-destroying fungal dregs, rice straw, tobacco straw, plant ash, chicken, and sheep manure. The novel BIO was found to be effective in controlling grass and broad-leaved weeds in three rice fields (Huanan, Hainan, and Heilongjang, in China) for 2 years (2014 and 2015) with an average rate of more than $80 \%$ weed suppression. In addition, the BIO treatments significantly increased rice yield (16.3\%-29.8\% relative to the control) and yield components (e.g., number of spikes per square meter, plant height, and number of kernels per spike) (Li et al. 2018). However, the BIO effects on soil bacterial community, functional capability and soil chemical properties in multisite soil rice paddy are not well known. In this study, we evaluated: (1) the influence of BIO on soil bacterial community and soil enzyme and (2) the relationships among BIO, soil bacterial community and location (longitude and latitude). Results from this study lay a theoretical foundation for BIO applications.

\section{Materials and methods \\ Bio-organic fertilizer (BIO) manufacturing}

The organic substrates in the BIO consisted of kitchen garbage, maize straw, wood-destroying fungal dregs, rice straw, tobacco straw, plant ash, and chicken and sheep manure. The physical and chemical properties of the compost material are provided in our previous study ( $\mathrm{Li}$ et al. 2018). The combined process of ZF-5.5 fertilizer mechine (Changsha Beye Agricultural Ltd, China) preparation and pile fermentation was used to produce composting manure under a temperature range of $40-80^{\circ} \mathrm{C}$ for 15 days. Man-made heating and cooling was used to control temperature on the first day. The compost was moved out form the ZF-5.5 fertilizer mechine and piled fermentation began one day later. After 15 days, the compost turned taupe gray, exhibited threadiness and had a slightly sour fragrance. This compost contained 53.4\% organic matter, $2.0 \% \mathrm{~N}, 3.7 \% \mathrm{P}_{2} \mathrm{O}_{5}$, and $1.1 \% \mathrm{~K}_{2} \mathrm{O}$.

\section{Study site description}

Our multi-site study was conducted in five rice paddies in China, which had already been in use for 30 years. The location, altitude, temperate climate, and growing season of these study sites have been given in Table 1 .

\section{Field experiment and soil sample collection}

For each site, field trials were conducted on six $30 \mathrm{~m} \times 20 \mathrm{~m}$ plots from April 25-27 to Oct. 18-23, 2018 . Two or three 20-days old rice seedlings were transplanted to each hill per plot with $15 \mathrm{~cm} \times 15 \mathrm{~cm}$ inter spacing seedlings in plot. The rice varieties selected were Chuanyou 6203 at Guizhou (GZ), Xiangeng 2369 at Henan (HN), Yuzhenxiang at Hainan sanya (SY), Longgeng 29 at Heilongjiang (HLJ) and Nangeng 9108 at Jianshu (JS). Three days after transplanting, BIO (3000 kg/ha) were spread over three plots as the treatment. Our choice of BIO dosage was based on results from our previous study which showed this dosage to be the most effective and economical for weed control ( $\mathrm{Li}$ et al. 2018). The other plots were not supplied with BIO fertilizer. The base fertilizer was applied uniformly in six BIO-treatments and untreated plots. All field management practices followed local and traditional practices, except for the irrigation during BIO application, as a $3-5 \mathrm{~cm}$ water layer had to be maintained for 7 days. Rice plants were maintained as per site local agronomic practices. No top dressing or other weed control strategies were carried out in the 
Table 1 Description of the study sites

\begin{tabular}{|c|c|c|c|c|c|}
\hline Site & Soil type & Latitude longitude & Altitude & Temperate climate & Growing season \\
\hline Hainan (SY) & Latosol & $\begin{array}{l}\mathrm{N} 18^{\circ} 23^{\prime} 30^{\prime \prime} \\
\mathrm{E} 109^{\circ} 11^{\prime} 33^{\prime \prime}\end{array}$ & $9 m$ & $22-28$ & April-November \\
\hline Henan (HN) & Yellow Brown Soil & $\begin{array}{l}N 31^{\circ} 49^{\prime} 52^{\prime \prime} \\
\text { E114 } 14^{\circ} 04^{\prime} 79^{\prime \prime}\end{array}$ & $87 \mathrm{~m}$ & $25-34$ & April-October \\
\hline Heilongjiang (HしJ) & Black Soil & $\begin{array}{l}\text { N } 45^{\circ} 97^{\prime} 82^{\prime \prime} \\
\text { E128 } 78^{\circ} 45^{\prime} 40^{\prime \prime}\end{array}$ & $196 \mathrm{~m}$ & $24-30$ & May-November \\
\hline Jiangsu (JS) & Yellow Brown Soil & $\begin{array}{l}\text { N } 31^{\circ} 35^{\prime} 49^{\prime \prime} \\
\text { E } 119^{\circ} 10^{\prime} 57^{\prime \prime}\end{array}$ & $8 \mathrm{~m}$ & $26-37$ & April-October \\
\hline Guizhou (GZ) & Yellow Cinnamon Soil & $\begin{array}{l}\mathrm{N} 27^{\circ} 54^{\prime} 34^{\prime \prime} \\
\text { E106 } 74^{\prime} 78^{\prime \prime}\end{array}$ & $1271 \mathrm{~m}$ & $20-34$ & May-November \\
\hline
\end{tabular}

Soil types were classified according to China soil classification system (GB/T 17296-2009)

experimental plots. Soil samples were collected from all plots on May 25-27, 2018, i.e. 1 month after BIO application. One hundred grams of surface soil $(0-15 \mathrm{~cm})$ was collected from 45 points and 15 samples were mixed together in 15 plastic bags from each plot. Soil samples were divided into two parts, one part was frozen and stored at $-80{ }^{\circ} \mathrm{C}$, and the other part was air dried for 1 week and stored at $25^{\circ} \mathrm{C}$.

\section{Soil chemical properties measurements}

Soil pH was measured in soil-water solution (W/V 1:5). Soil total $\mathrm{N}$ and $\mathrm{K}$ content were measured using an elemental analyzer (Carlo Erba, Milan, Italy) and total $\mathrm{P}$ content was assayed calorimetrically by the molybdate method (Willy et al. 2019). Other chemical properties which included hydrolytic $\mathrm{N}$, extractable $\mathrm{P}$, exchangeable $\mathrm{K}$, and organic matter content were analyzed as described previously (Ballabio et al. 2019).

\section{DNA extraction and library construction}

Total genomic DNA was extracted using DNA extraction kit following the manufacturer's instructions. The quality and quantity of DNA was verified with NanoDrop and agarose gel. Extracted DNA was diluted to a concentration of $1 \mathrm{ng} / \mu \mathrm{l}$ and stored at $-20^{\circ} \mathrm{C}$ until further processing. The diluted DNA was used as template for PCR amplification of bacterial 16S rRNA genes with the barcoded primers and Takara Ex Taq (Takara Bio, JP). For bacterial diversity analysis, V3V4 variable regions of 16S rRNA genes were amplified with the following primer pair: 343F-(5'-TACGGRAGGCAGCAG-3') and 798R-(5'-AGGGTATCTAATCCT-3').

Amplicon quality was visualized using gel electrophoresis, purified with AMPure XP beads (Bechman Couter, USA), and amplified for another round of PCR. After a second round of purification with the AMPure XP beads, the final amplicon was quantified using Qubit dsDNA assay kit (Takara Bio, JP). Equal amounts of purified amplicon were pooled for subsequent sequencing.

\section{Bioinformatics and statistical analysis}

Raw sequencing data were in FASTQ format. Paired-end reads were then preprocessed using Trimmomatic software to detect and cut off ambiguous bases (N) (Tao et al. 2018). It also cut off low quality sequences with average quality score below 20 using the sliding window trimming approach. After trimming, the paired-end reads were assembled using the FLASH software (http://ccb. jhu.edu/software/FLSH/). Parameters of assembly were: $10 \mathrm{bp}$ of minimal overlapping, $200 \mathrm{bp}$ of maximum overlapping and $20 \%$ of maximum mismatch rate. Sequences were further performed with denoising as follows: reads with ambiguous, homologous sequences or below $200 \mathrm{bp}$ were abandoned. Reads with $75 \%$ of bases above Q20 were retained. Then, reads with chimera were detected and removed. These two steps were achieved using QIIME software (version 1.8.0, http://qiime.org/).

Clean reads were subjected to primer sequences removal and clustering to generate operational taxonomic units (OTUs) using the V search software with 97\% similarity cutoff. The representative read of each OTU was selected using QIIME package. All representative reads were annotated and blasted against the Silva database Version 123 (or Greengens) (16 s/18 s rDNA) using RDP classifier (confidence threshold was 70\%). The alpha diversity indices (Chao1 and Shannon index) were calculated using QIIME in R software (GomezSagasti et al. 2019). Principal component analysis (PCA) was performed using CANOCO 5.0. Analysis of variance (ANOVA) test was conducted with Genstat 13 (VSN International, Hemel Hemspstead, UK) to evaluate the effect of BIO treatment and control on the five sites. The relative abundance of OTU was inferred with FUNGuild (Wang et al. 2020). Significant differences in bacterial species were determined using the linear discriminant 
analysis (LDA) effect size (LEfSe) method with KruskalWallis sumrank test. Differences were considered statistically significant at a level of $p<0.05$. Phylogenetic analysis of communities by reconstruction of unobserved states (PICRUSt) analysis with the KEEG orthology database was used to predict and visualize bacterial function on the significant difference between bacteria. Redundancy analysis (RDA) was carried out in R, to determine the correlation among relative abundance of bacterial community, soil chemical properties, and site location.

\section{Soil enzymatic activity determination}

Five soil samples from treated and untreated sites were analyzed for three representative enzymes activities (soil urease (S-UE), soil acid phosphatase (S-ACP) and soil $\beta$-glucosidase ( $\mathrm{S}-\beta$-GC). Soil enzyme activities were analysed with the S-UE, S-ACP, and S- $\beta$-GC assay kit (Solarbio life Sciences, Beijing, China). S-UE was defined as $1 \mathrm{~g}$ of soil which produced $1 \mu \mathrm{g} \mathrm{NH}_{3}-\mathrm{N}(\mathrm{U} / \mathrm{g})$ daily. S-ACP was considered to be $1 \mathrm{~g}$ of soil which liberated $1 \mathrm{nmol}$ phenol at $37^{\circ} \mathrm{C}(\mathrm{U} / \mathrm{g})$ daily. S- $\beta-\mathrm{GC}$ was considered to be $1 \mathrm{~g}$ of soil which produced $1 \mu \mathrm{mol}$ p-nitroohenol $(\mathrm{U} / \mathrm{g})$ daily (Dick et al. 2013). All enzyme assays were conducted in duplicate.

\section{Results}

\section{Effect of BIO on soil chemical properties}

The effects of BIO on soil chemical properties in the five sites are presented in Table 2. No significant differences were observed between BIO treatment and untreated plots for soil $\mathrm{pH}$, the total $\mathrm{N}$, total $\mathrm{K}$ and total $\mathrm{P}$ at all five rice paddy sites. The hydrolytic $\mathrm{N}$ and organic matter of the soil with $\mathrm{BIO}$ treatment were respectively lower than for untreated soil at JS and HN sites. The other sites were not affected. The exchangeable $\mathrm{K}$ was higher in the BIO treatment $(193 \mathrm{mg} / \mathrm{kg}$ and $243 \mathrm{mg} / \mathrm{kg})$ than untreated plot $(152 \mathrm{mg} / \mathrm{kg}$ and $142 \mathrm{mg} / \mathrm{kg})$ at JS and GZ site rice paddy. The exchangeable $\mathrm{K}$ was not significantly different between treatments and control in the HLJ and SY sites. The exchangeable $\mathrm{K}$ of $\mathrm{BIO}$ soil was $23.66 \%$ lower than untreated soil. The exchangeable $\mathrm{K}$ was irregularly affected by $\mathrm{BIO}$ at the five sites. The extractable $\mathrm{P}$ also showed irregularity in its influence by $\mathrm{BIO}$ in the five rice paddy sites.

\section{Composition of soil bacterial community at the study sites} Sequencing of the 16S rRNA genes revealed the bacterial diversity and community composition in the five sites of the rice paddies. The number of OTUs in all samples was 1660-4621 and the mean length of valid tags was 409.98419.42 bp in all samples (Additional file 1: Fig. S1). Bacterial community structure at the phylum level in the BIO-treated soil and untreated soil samples is shown in Fig. 1a. The five most dominant phyla in HN soil samples were Proteobacteria, Bacteroidetes, Actinobacteria, Nitrospirae, and Acidobacteria. The five most dominant phyla in JS soil samples were Proteobacteria, Actinobacteria, Bacteroidetes, Acidobacteria, and Gemmatimonadetes. The five most dominant phyla were Proteobacteria, Bacteroidetes, Actinobacteria, Firmicutes, and Acidobacteria in HLJ, GZ, and SY soil samples. Bacterial community structure (at the genus level) in the BIO-treated and untreated soil samples is shown in Fig. 1b. The five most dominant genuses in HN soil samples were Anaeromyxobacter, Haliangium, Geobacter, Ellin6067, and Thiobacillus. The five most dominant genus in JS soil samples were Anaeromyxobacter, Haliangium, Ellin6067, Geobacter, and Nocardioides. The five most dominant genus in HLJ soil samples were Anaeromyxobacter, Gouta6, Geobacter, Clostridium_sensu_stricto_1, and Ellin6067. The five most dominant phyla in GZ soil samples were Escherichia-Shigella, Bifidobacterium, Anaeromyxobacter,

Table 2 Chemical properties of the surface soil layer $(0-15 \mathrm{~cm})$ with the BIO-treatment and control in five sites

\begin{tabular}{|c|c|c|c|c|c|c|c|c|}
\hline Variable source & $\mathrm{pH}$ & $\begin{array}{l}\text { Total K } \\
\mathrm{mg} / \mathrm{kg}\end{array}$ & $\begin{array}{l}\text { Total N } \\
\mathrm{mg} / \mathrm{kg}\end{array}$ & $\begin{array}{l}\text { Total P } \\
\mathrm{mg} / \mathrm{kg}\end{array}$ & $\begin{array}{l}\text { Exchangeable } \mathrm{K} \\
\mathrm{mg} / \mathrm{kg}\end{array}$ & $\begin{array}{l}\text { Extractable } P \\
\mathrm{mg} / \mathrm{kg}\end{array}$ & $\begin{array}{l}\text { Hydrolytic N } \\
\mathrm{mg} / \mathrm{kg}\end{array}$ & $\begin{array}{l}\text { Organic matter } \\
\mathrm{mg} / \mathrm{kg}\end{array}$ \\
\hline $\mathrm{HN}-\mathrm{CK}$ & $5.42 \mathrm{a}$ & $17.9 a$ & $2.33 a$ & $0.42 a$ & $131 a$ & $0.26 a$ & $233 a$ & $34.1 a$ \\
\hline HN-TRE & $5.33 a$ & $17.8 \mathrm{a}$ & $1.55 b$ & $0.36 a$ & $100 b$ & $0.26 a$ & $161 b$ & $26.1 b$ \\
\hline JS-CK & $6.13 a$ & $13.4 \mathrm{a}$ & $1.37 a$ & $0.46 a$ & $152 b$ & $2.26 a$ & $174 a$ & $18.8 a$ \\
\hline JS-TRE & $6.60 a$ & $14.7 a$ & $1.15 a$ & $0.50 a$ & $193 a$ & $1.87 b$ & $120 b$ & $14.8 b$ \\
\hline HLJ-CK & $5.54 a$ & $21.8 \mathrm{a}$ & $1.70 a$ & $0.82 a$ & $131 a$ & 1.406 & $179 a$ & $34.0 \mathrm{a}$ \\
\hline HLJ-TRE & $5.73 a$ & $21.7 a$ & $1.73 a$ & $1.00 \mathrm{a}$ & $128 a$ & $8.91 a$ & $150 a$ & $32.1 \mathrm{a}$ \\
\hline GZ-CK & $5.94 a$ & $15.3 a$ & $2.16 a$ & $0.91 a$ & $142 b$ & $4.25 a$ & 180a & $34.3 a$ \\
\hline GZ-TRE & $6.47 a$ & $16.7 a$ & $2.23 a$ & $1.06 a$ & $243 a$ & $5.30 a$ & $182 \mathrm{a}$ & $36.6 a$ \\
\hline SY-CK & $6.30 a$ & $10.0 b$ & $1.03 a$ & $0.41 a$ & $121 a$ & $2.17 a$ & $155 a$ & $15.5 a$ \\
\hline SY-TRE & $6.35 a$ & $13.1 a$ & $1.12 \mathrm{a}$ & $0.34 a$ & $128 a$ & $2.01 a$ & $117 a$ & $16.1 \mathrm{a}$ \\
\hline
\end{tabular}

Italic values represent $p<0.05$

Values show mean $(\mathrm{n}=3)$. Means with different letters represent significant differences at $p<0.05$ 


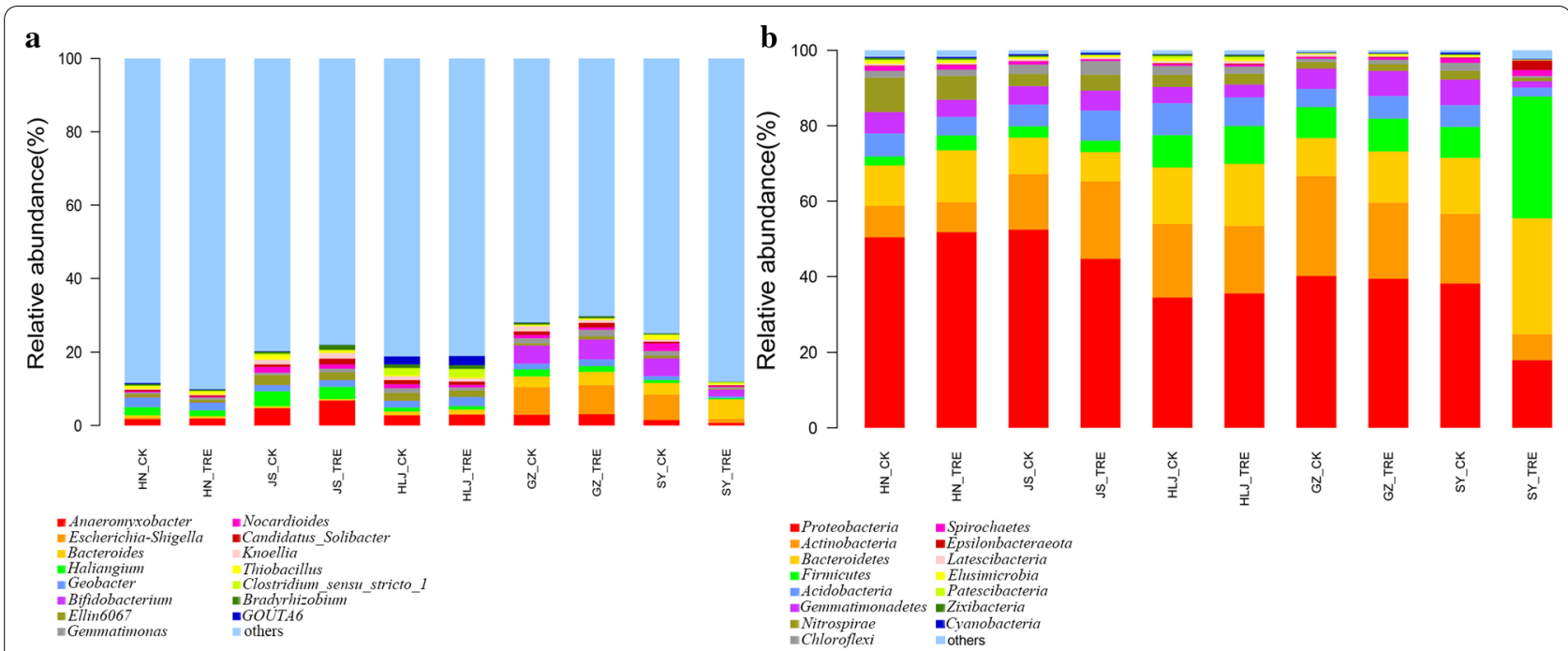

Fig. 1 Relative abundances (\%) of bacterial composition (phyla and genera level) in BIO-treated and untreated soil samples at five rice paddy sites. a Relative abundance of the top 15 phyla among the BIO-treated soil samples. $\mathbf{b}$ Relative abundance of the top 15 genera among the BIO-treated soil samples. The HN_CK, HN_TRE, JS_CK, JS_TRE, HLJ_CK, HL__TRE, GZ_CK, GZ_TRE, SY_CK and SY_TRE represent BIO treated and untreated control at the five rice paddy sites in China

Bacteroides and Haliangium. The five most dominant genus in SY soil samples were Escherichia-Shigella, Bacteroides, Bifidobacterium, Anaeromyxobacter, and Nocardioides. Hence, the main phyla were Proteobacteria, Actinobacteria, Bacteroidetes, Firmicutes and Acidobacteria, and the main genus were Anaeromyxobacter, Escherichia-Shigella, Bacteroides, Haliangium, and Geobacter in the five rice paddies.

\section{Soil bacterial community diversity of the study sites}

The alpha diversity indices (Chaoland Shannon) of the different soil treatments (BIO-treatment and untreated control) are shown in Fig. 2. The Chao1 indices indicated that any soil treatments of one site was not significantly separated $(p<0.05$, Fig. 2a) and the Shannon indices also indicated $d$ that the overall bacterial species were not significantly separated ( $p<0.05$, Fig. $2 \mathrm{~b})$ among the BIO-treated and untreated soil samples at any one site. The indices were not significantly different among the BIO-treated and untreated soil samples. The PCA of beta diversity indicated that all replicates of treated soils (BIO samples and untreated soil samples) clustered together (Fig. 3). The soil treatments of HN, HLJ, and JS site was not significantly separated $(p<0.05)$ and the GZ and SY also verified that the overall bacterial species were significantly separated $(p<0.05)$ among the BIO-treated and untreated soil samples at any one site. The PCA of beta diversity showed that the BIO treatment had minor influence on the beta diversity.

\section{Changes in the soil bacterial community}

To investigate the effects of $\mathrm{BIO}$ on the changes in soil bacterial community, ANOVA test was used to identify differential abundance between BIO-treatment and untreated control in five site soils (Additional file 1: Fig. $\mathrm{S} 1$ ). At the phylum level, the top 10 significantly differences abundant bacteria were Acidobacteria, Actinobacteria, Bacteroidetes, Chloroflexi, Epsilonbacteraeota, Firmicutes, Gemmatimonadetes, Nitrospirae, Proteobacteria and Spirochaetes. At the genus level, the significantly difference bacteria were Anaeromyxobacter, Bacteroides, Bifidobacterium, Escgerichia-Shigella, Geobacter, and Haliangium. LEfSe analysis identified 47 differentially abundant phyla and 963 differentially abundant genus with LDA scores $>2$ (Fig. 4). There were 12 phyla in $\mathrm{SY}_{-}$ CK and SY_TR with LDA scores $>5$. The most significant contribution of BIO on the soil community in the SY site was the enhancement of the abundance of Gammaproteobacteria (at phylum level). In addition, enhancement of the abundance of Proteobacteria and Deltaproteobacteria were the major effects BIO had on the soil community in JS_CK and JS_TR. Of the 15 phyla in HN_CK and HN_TR with LDA scores $>4$, the key contributor of BIO effect on soil community were Alphaproteobacteria and Nitrospirae. Nine phyla in HLJ and 7 phylum in GZ with LDA scores $>4$, the effect BIO had on the soil community, was the enhancement of the abundance of Acidobacteria and Actinobacteria, respectively.

Based on the KEEG data, 6 functional gene families were predominant and accounted for metabolism 

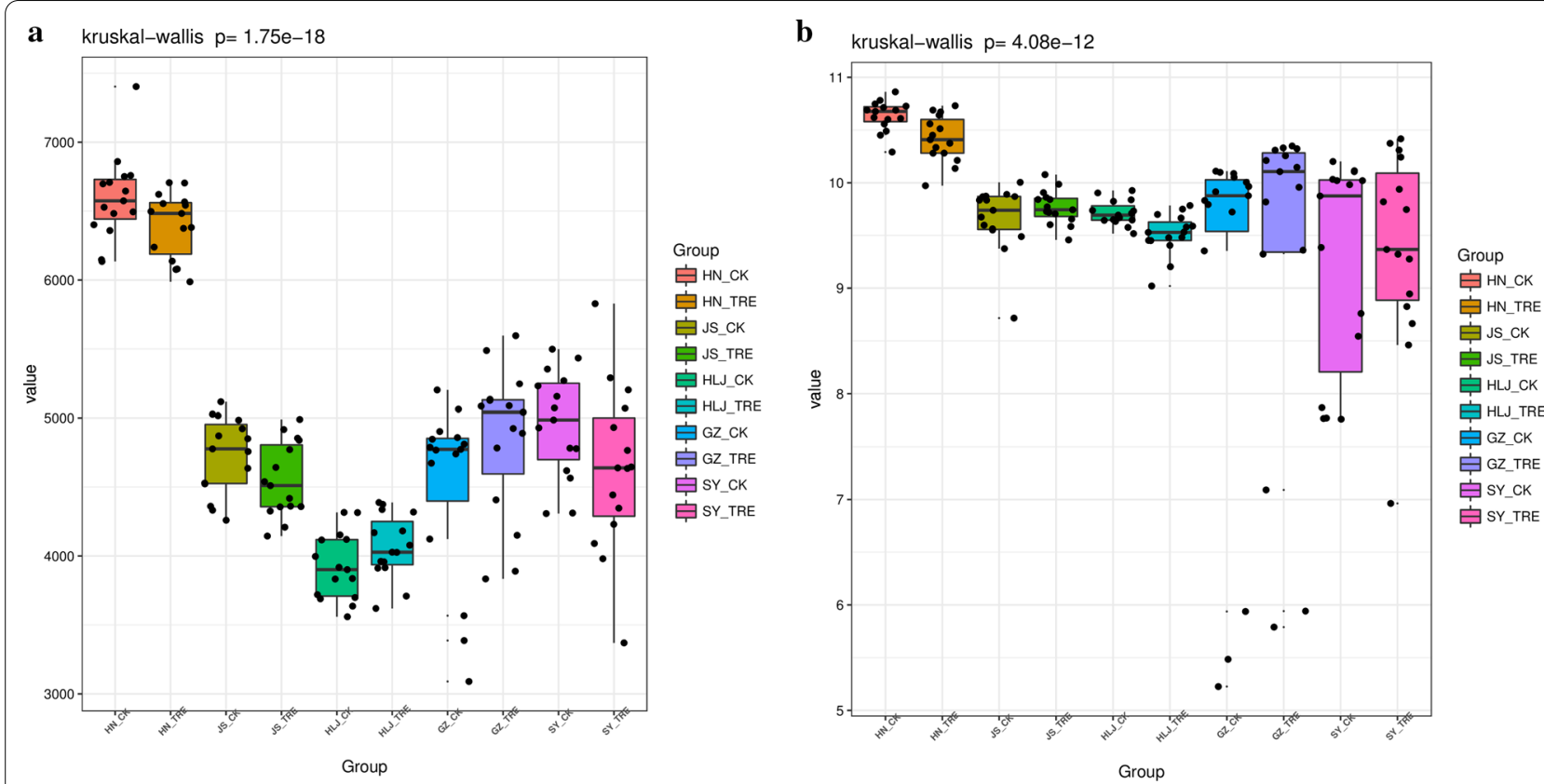

Fig. 2 Alpha-diversity indices, a Chaol and $\mathbf{b}$ Shannon indices, of the bacterial community structure in BIO-treated and untreated soil samples at five rice paddy sites. The HN_CK, HN_TRE, JS_CK, JS_TRE, HLJ_CK, HL__TRE, GZ_CK, GZ_TRE, SY_CK and SY_TRE represent BIO treatment and untreated control at the five rice paddy sites in China

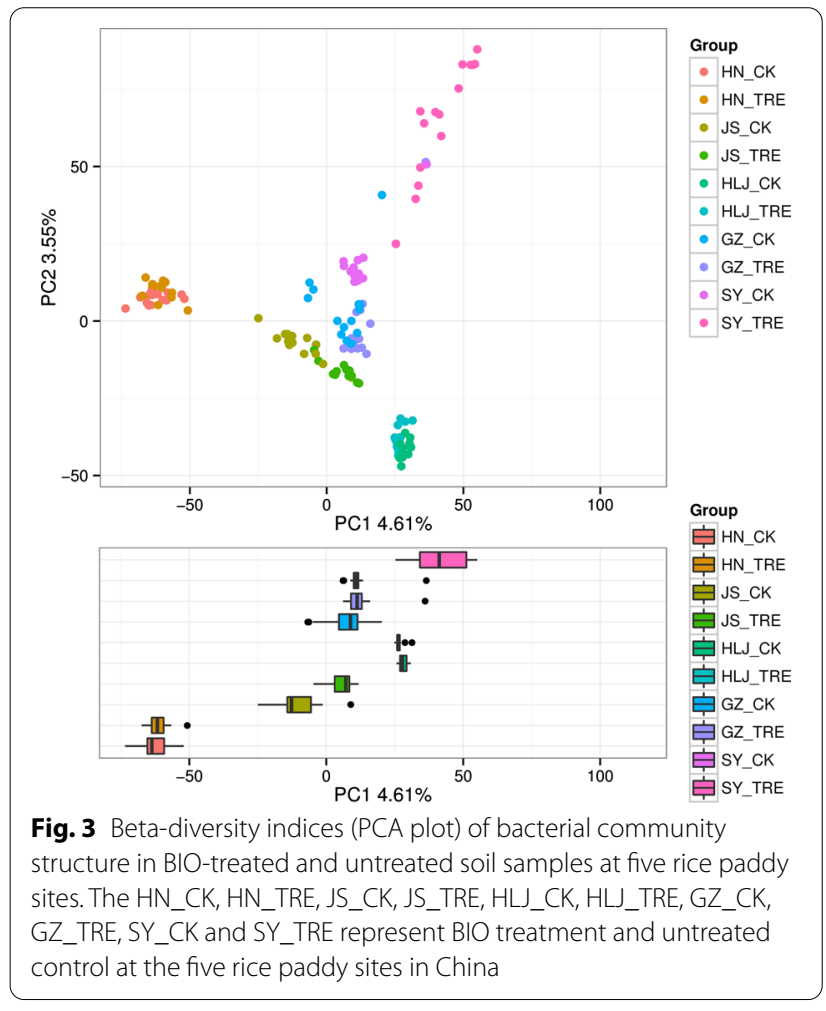

(50.69\%), genetic information processing $(16.29 \%)$ and environmental information processing (13.25\%), at KEGG level 1 (Additional file 1: Fig. S2). At KEGG level 2 , a total of 41 sub-functional gene families were identified to be involved in cell communication, sensory system and amino acid metabolism (Additional file 1: Fig. S3). In brief, only cell communication $(p>0.01)$ and sensory system $(p>0.01)$ were significantly reduced in all study sites. The other 39 sub-functional gene families were not concurrently affected at all the study sites. From baslt EggNOG data, a total of 25 functional clusters of COG (Clusters of Orthologous Groups, https://www.ncbi. nlm.nih.gov/COG/) were predicted in all sites (Fig. 5). In brief, the relative abundance of COG gene was enhanced by the BIO treatment in all sites. The top 3 functional clusters were general function prediction only $(\mathrm{R})$, amino acid transport and metabolism (E) and transcription (K) in all study sites. The abundance of genes related to COG was similar between BIO treatments and controls at the multisites in China rice paddies.

\section{Relationships of the bacterial community with soil chemical properties and site locations}

The correlation among bacterial community, soil chemical properties, and site locations is shown in Fig. 6 and Table 3. We observed significant positive correlations among northern latitude, eastern longitude, exchangeable $\mathrm{K}$, total $\mathrm{K}$, total $\mathrm{P}$, soil $\mathrm{pH}$, and total $\mathrm{N}$ in our study, 


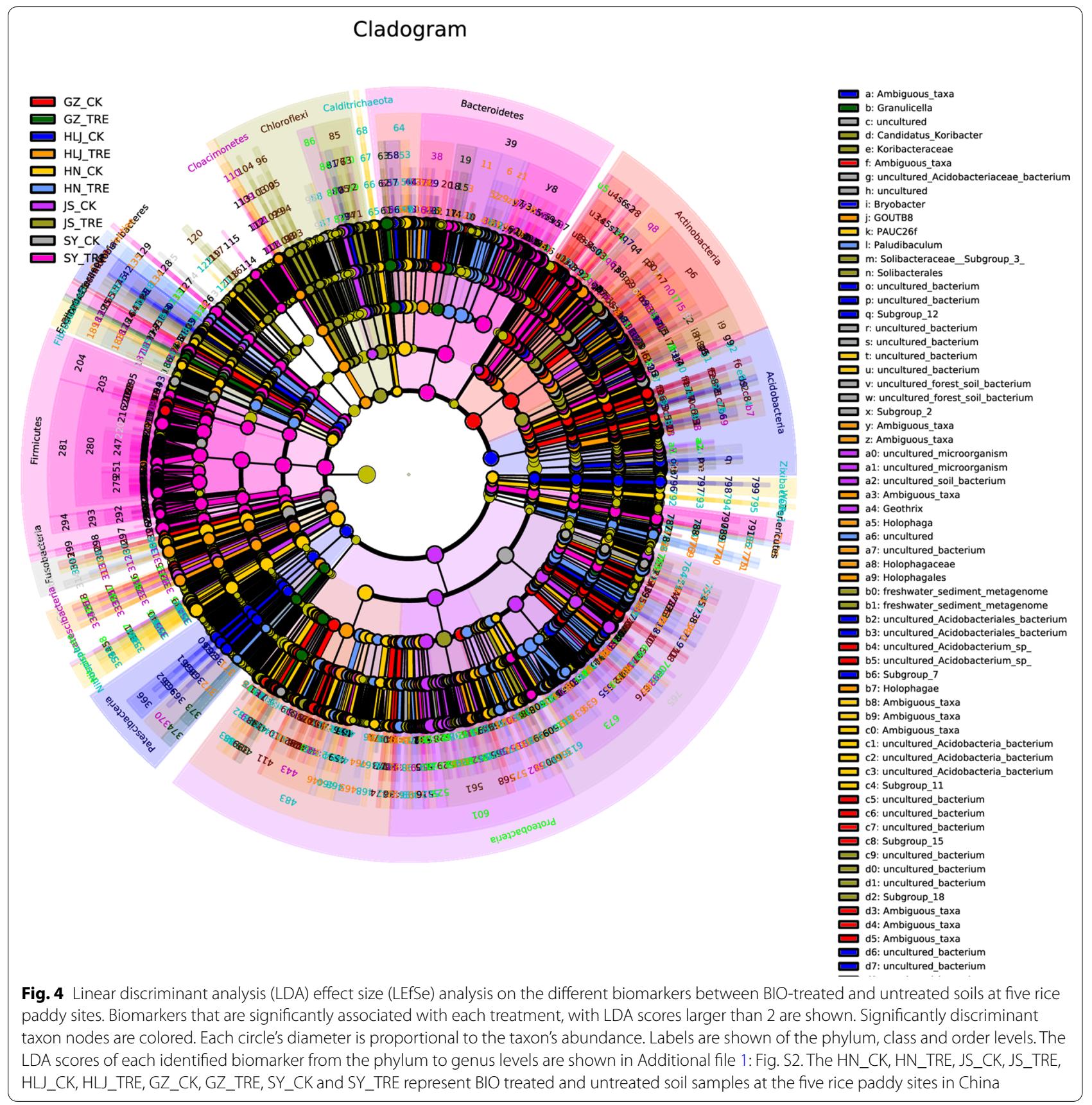

except for organic matter, hydrolytic $\mathrm{N}$ and extractable P. The northern latitude and eastern longitude of rice paddy sites were positively related to the abundance of Escherichia.Shigella $(p=0.022$ and 0.001), Bifidobacterium ( $p=0.007$ and 0.001), Ellin6067 $(p=0.007$ and 0.006), GOUTA6 ( $p=0.006$ and 0.046), Pesudolabrys ( $p=0.039$ and 0.010$)$, Acidothermus $(p=0.030$ and $0.036)$, Klebsiella $(p=0.069$ and 0.069$)$ and Fodinicola $(p=0.002$ and 0.001$)$. In addition, exchangeable $\mathrm{K}$ significantly correlated with Anaeromyxobacter $(p=0.001)$
Candidatus_Solibacter $(p=0.004)$, Knoellia $(p=0.021)$, Bradyrhizobium $(p=0.028)$ and Candidatus_Koribacter $(p=0.047)$.

\section{Soil enzymatic activity}

The activities of three soil enzymes (S-UE, S-ACP and $S-\beta-G C)$ in the BIO-treated and untreated soil at five sites were not significantly different (Fig. 7). S-UE and S-ACP activity in BIO treated soil decreased when compared to its activities in untreated soil at the GZ, SY, HN 


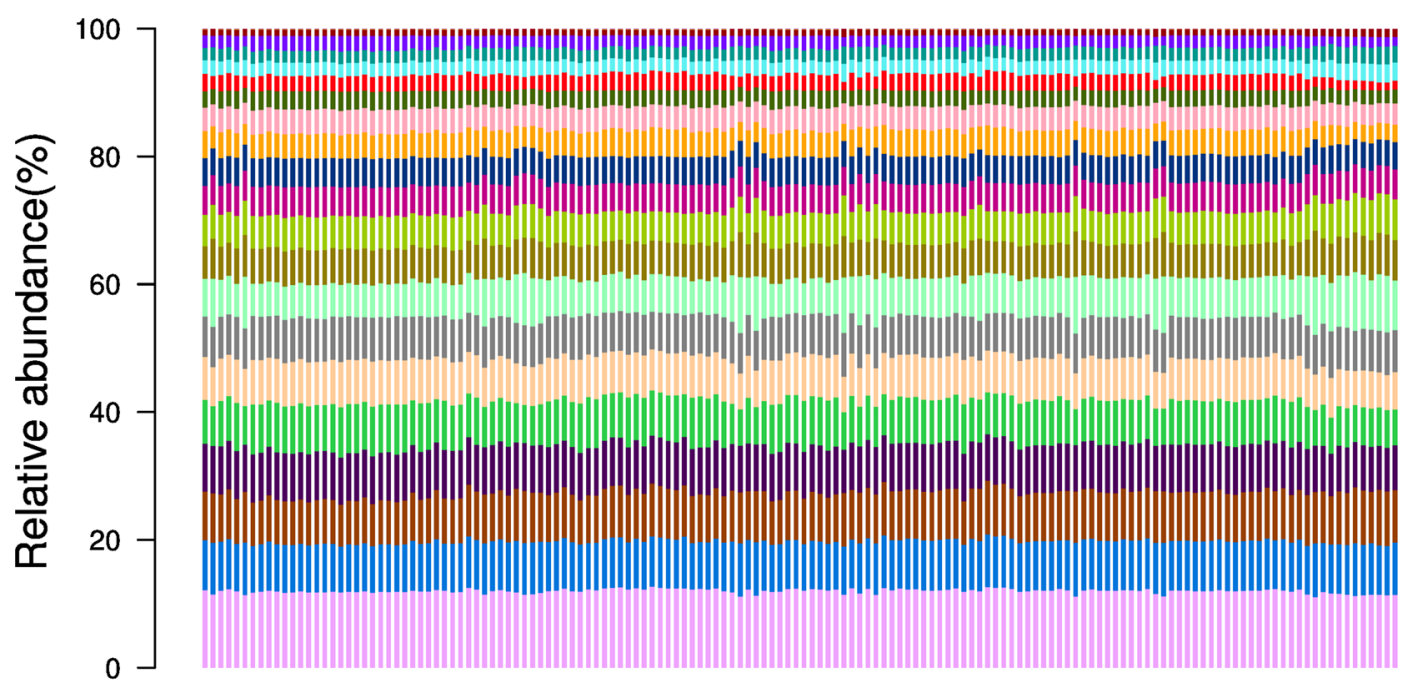

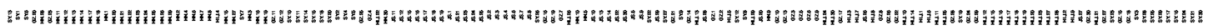

R: General function prediction only

E: Amino acid transport and metabolism

- K: Transcription

QS: Function unknown

T: Signal transduction mechanisms

C: Energy production and conversion

M: Cell wall/membrane/envelope biogenesis

G: Carbohydrate transport and metabolism

E: Replication, recombination and repair

J: Translation, ribosomal structure and biogenesis

-P: Inorganic ion transport and metabolism

- H: Coenzyme transport and metabolism

I: Lipid transport and metabolism

Fig. 5 Clusters of orthologous groups of proteins (COG) functional prediction of the significantly different abundant bacteria between BIO-treated and untreated soil samples at five rice paddy sites. The HN_CK, HN_TRE, JS_CK, JS_TRE, HLJ_CK, HLJ_TRE, GZ_CK, GZ_TRE, SY_CK and SY_TRE represent $\mathrm{BIO}$ treatedt and untreated soil samples at the five rice paddy sites in China

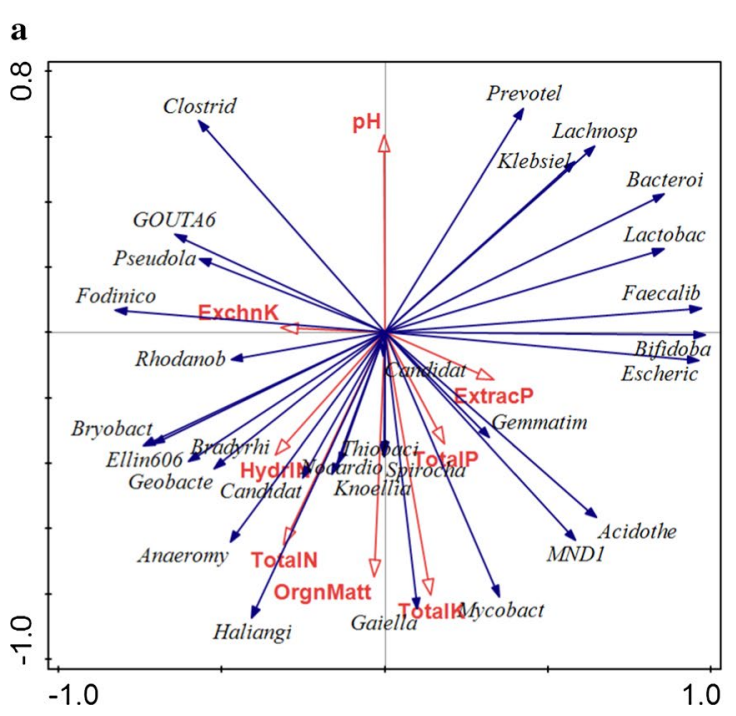

b

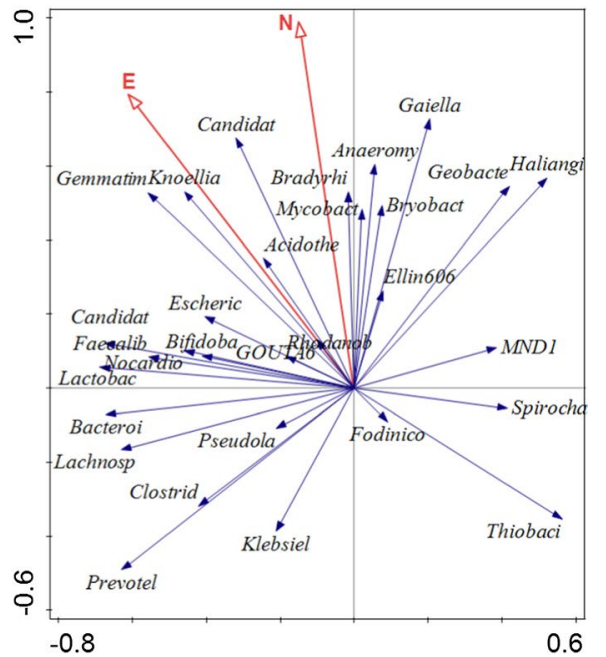

Fig. 6 Redundancy analysis (RDA) of microbial community and soil chemical properties ( $p$ value $=0.02$ ) between BIO-treated and untreated soil samples at five rice paddy sites. E: East longitude, N: Northern latitude, ExchnK: Exchangeable K, HydrlN: Hydrolytic N, ExtracP: Extractable P 
Table 3 Canonical correlation analysis among soil bacterial, soil chemical properties and soil sites

\begin{tabular}{|c|c|c|c|c|c|c|c|c|c|c|}
\hline Bacterial genus & Organic matter & $\begin{array}{l}\text { Hydrolytic } \\
\mathrm{N}\end{array}$ & Exchangeable $\mathrm{K}$ & $\mathrm{pH}$ & $\begin{array}{l}\text { Total } \\
\mathrm{N}\end{array}$ & Total P & Total K & $\mathrm{N}$ & $E$ & $\begin{array}{l}\text { Extractable } \\
P\end{array}$ \\
\hline Anaeromyxobacter & 0.865 & 0.838 & 0.001 & 0.331 & 0.560 & 0.044 & 0.657 & 0.216 & 0.407 & 0.401 \\
\hline Escherichia.Shigella & 0.527 & 0.418 & 0.116 & 0.037 & 0.243 & 0.360 & 0.200 & 0.022 & 0.001 & 0.231 \\
\hline Geobacter & 0.178 & 0.204 & 0.828 & 0.096 & 0.024 & 0.367 & 0.003 & 0.026 & 0.260 & 0.602 \\
\hline Bifidobacterium & 0.178 & 0.204 & 0.894 & 0.682 & 0.537 & 0.946 & 0.313 & 0.007 & 0.001 & 0.498 \\
\hline Ellin6067 & 0.892 & 0.707 & 0.206 & 0.811 & 0.682 & 0.279 & 0.279 & 0.007 & 0.006 & 0.881 \\
\hline Gemmatimonas & 0.313 & 0.349 & 0.166 & 0.331 & 0.448 & 0.035 & 0.973 & 0.702 & 0.367 & 0.121 \\
\hline Candidatus_Solibacter & 0.427 & 0.470 & 0.004 & 0.296 & 0.279 & 0.014 & 0.407 & 0.298 & 0.634 & 0.383 \\
\hline Knoellia & 1 & 0.838 & 0.021 & 0.407 & 0.759 & 0.073 & 0.919 & 0.335 & 0.449 & 0.336 \\
\hline Bradyrhizobium & 0.892 & 1 & 0.028 & 0.707 & 0.492 & 0.039 & 0.178 & 0.016 & 0.046 & 0.455 \\
\hline GOUTA6 & 0.178 & 0.263 & 0.947 & 0.014 & 0.066 & 0.232 & 0.001 & 0.006 & 0.046 & 0.841 \\
\hline Bryobacter & 0.492 & 0.537 & 0.089 & 1 & 0.218 & 0.049 & 0.049 & 0.009 & 0.058 & 0.894 \\
\hline Candidatus_Koribacter & 0.733 & 0.514 & 0.047 & 0.060 & 0.838 & 0.073 & 0.919 & 0.576 & 0.492 & 0.132 \\
\hline Pesudolabrys & 0.583 & 0.865 & 0.828 & 0.514 & 0.973 & 0.584 & 0.232 & 0.039 & 0.010 & 0.777 \\
\hline Acidothermus & 0.919 & 0.811 & 0.185 & 0.010 & 0.838 & 0.838 & 0.080 & 0.030 & 0.036 & 0.614 \\
\hline Klebsiella & 0.891 & 0.759 & 0.424 & 0.448 & 0.707 & 0.367 & 0.232 & 0.069 & 0.069 & 0.700 \\
\hline Fodinicola & 0.492 & 0.560 & 0.815 & 0.514 & 0.946 & 0.448 & 0.154 & 0.002 & 0.001 & 0.960 \\
\hline
\end{tabular}

N: Northern latitude; E: East longitude; Boldface: significance; Italic boldface: top effect on soil chemical properties and soil sites

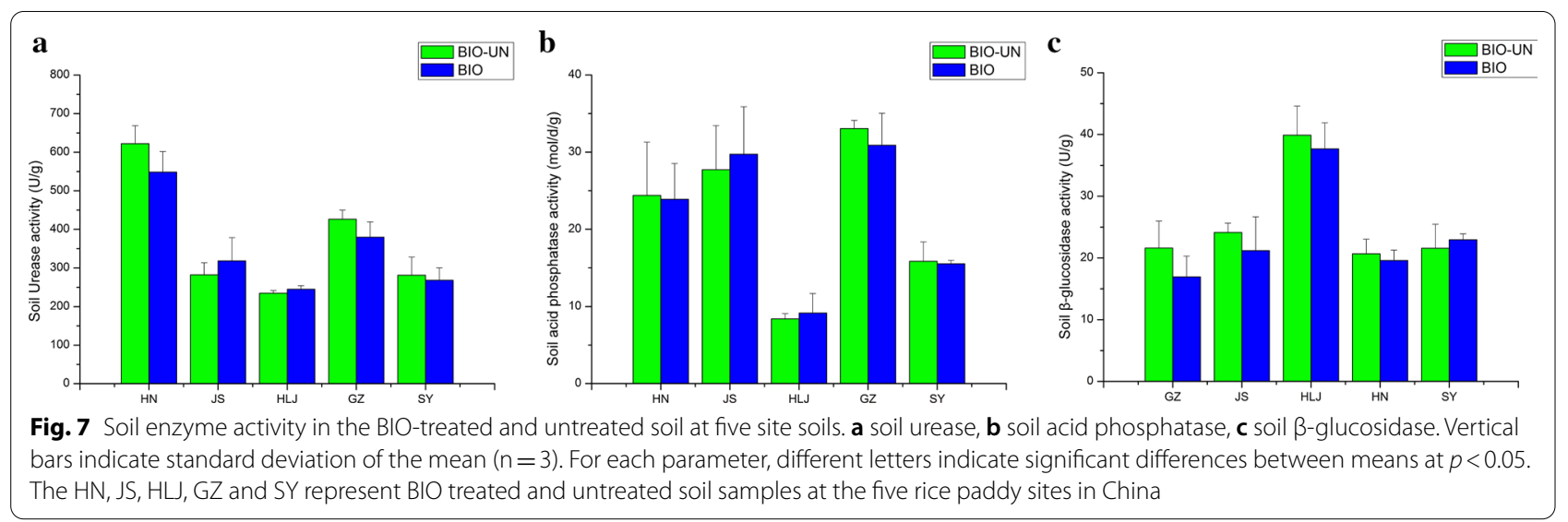

sites of rice paddies. On the contrary, S-UE and S-ACP exhibited opposite activity in the other sites (JS and HLJ). However, the BIO treated soil experienced decreased S- $\beta$-GC activity when compared to untreated soil at GZ, JS, HLJ, and HN sites except for the SY sites. In majority of the sites, the three enzyme activities under BIO-treatment were equivalent to that under untreated.

\section{Discussion}

In this study, we identified the main bacterial phyla (Proteobacteria, Actinobacteria, Bacteroidetes, Firmicutes and Acidobacteria) and genus (Anaeromyxobacter, Escherichia-Shigella, Bacteroides, Haliangium, and Geobacter) in five rice paddies in China. Proteobacteria was relatively the most abundant phylum in the soils of the five rice paddies located in Guizhou province (Southwestern China), and the other four phyla (Chloroflexi, Acidobacteria, Nitrospirae, and Bacteroidetes) were the dominant species in all samples. This result is consistent with that of a previous study (Sun et al. 2015). Results from the taxonomic analysis indicated that the Cyanobacteria and Proteobacteria were dominant phyla in four soils, collected from Changchun, Jiangdu, Yingtan, and Yanting rice paddies (Wang et al. 2019a, b). At Xiantang (Hunan Province, China), the dominant phyla were Proteobacteria (39.98\%), Chloroflexi (17.10\%) and Actinobacteria (12.70\%) out of the total 41 phyla of bacterial community structure in the rice paddy (Guo et al. 2019). 
At Hengyang (Hunan Province, China), the Proteobacteria, Acidobacteria, Nitrospirae, Gemmatimonadetes, and Verruco- microbia were the dominant phyla of bacterial community structure in three rice-based cropping paddies (Huang et al. 2020). From the above reports, we deduce that the dominant soil bacterial species were similar in all the major rice-growing areas in China. Hence, application of BIO did not change the soil bacterial structure within these rice paddies.

It is generally accepted that farming practices cause changes in the soil microbial community (Zwetsloot et al. 2020). Likewise, BIO application caused changes in the soil microbial communities in all the five rice paddies and the dominant and most abundant bacteria present included Gammaproteo-bacteria, Proteobacteria, Deltaproteobacteria, Alphaproteobacteria, Nitrospirae, Acidobacteria, and Actinobacteria. Meanwhile, the top three functions of the bacteria in all study sites were only of general function prediction, amino acid transport and metabolism and transcription. Land-use changes of desert soils resulted into a significant decrease in Alphaproteobacteria, Actinodbacteria, Bacteroidetes and Firmicutes and sharply increased Acidobacteria, Chlorflexi, Nitrospira and Gammaproteobacteria (Wang et al. 2012). The phylum Bacteroidetes and Acidobacteria were increased, while Actinobacteria and Firmicutes decreased under combined antibiotics (sulfadiazine, sulfamethoxazole, trimethoprim, florfenicol, and clarithromycin) treatment in rice system (Uddin et al. 2019). Amino acid transport and metabolism was significantly different among the soils in the paddies under four common fertilizer treatment and control without fertilizer treatment (Wang et al. 2019a, b). Similar to these studies, soil bacterial community and function were slightly different between application of $\mathrm{BIO}$ and untreated plots in the five rice paddies.

Farming practices commonly cause changes in soil chemical properties and enzyme activity (Kumar et al. 2020). However, there were minor modifications after application of BIO in the five rice paddies (Table 2, Fig. 7). This result is in agreement with other studies. For instance, soil chemical properties and enzyme activity differed significantly between the organic site and conventional site, while no changes were stimulated in response to lupin (Lupinus angustifolius) amendment at 4 and $8 \mathrm{t}$ level during short-term incubation (Stark et al. 2008). Also, the soil properties at a rice-rice rotation producing area in china did not show differences between optimum reduced fertilization (OPT) treatments and unfertilized control (CK) and the soil $\mathrm{pH}$, total phosphorus, and total potassium showed no significant differences among all treatments under a long-term fertilization field experiment at rice-rice rotation producing area in China (Zhu et al. 2019). The activities of urease and acid phosphatase in the mesotrione-treated and control soil were not different from 2nd to 20th day after application (Du et al. 2018). The silver nanoparticles (AgNPs) had minor influence on the soil physico-chemical properties and enzyme activities (Oca-Vasquez et al. 2020). Similarly, the application of BIO in our study did not change the main soil chemical properties and enzyme activity in China rice paddies.

The present study demonstrated how BIO influenced bacterial community, soil enzyme and soil chemical properties. Application of BIO did not change the main soil bacterial phyla and genus, but resulted in a slightly different bacterial community and minor modification of soil enzyme and chemical properties in the rice paddies. These finding suggests that BIO application may be a sustainable weed management strategy in rice system. Future research under long-term field studies at multiple sites in rice paddies will shed more light on our findings.

\section{Abbreviations}

BIO: Novel bioorganic fertilizer; CBF: Common fertilizer; RDA: Redundancy analysis; PCA: Principal coordinates analysis; EF: Control effect.

\section{Supplementary Information}

The online version contains supplementary material available at https://doi. org/10.1186/s13568-021-01241-5.

Additional file 1: Figure S1. The number of OTUs and mean length of valid tags between $\mathrm{BIO}$ treated and untreated in five sites. The HN CK HN_TRE, JS_CK, JS_TRE, HLJ_CK, HLJ_TRE, GZ_CK, GZ_TRE, SY_CK and SY_TRE represent $\mathrm{BIO}$ treated and untreated control at the five rice paddy sites in China. Figure S2. KEGG level 1 analysis sub-functional gene families between BIO treated and untreated in five sites. The HN_CK, HN_TRE, JS_CK, JS_TRE, HLJ_CK, HLJ_TRE, GZ_CK, GZ_TRE, SY_CK and SY_TRE represent $\mathrm{BIO}$ treated and untreated control at the five rice paddy sites in China. Figure S3. KEGG level 2 analysis sub-functional gene families between BIO treated and untreated in five sites. The HN_CK, HN_TRE, JS CK, JS TRE, HLJ CK, HLJ TRE, GZ CK, GZ TRE, SY CK and SY TRE represent $\mathrm{BIO}$ treated and untreated control at the five rice paddy sites in China.

\section{Acknowledgements}

Not applicable.

\section{Authors' contributions}

LYB and ZRL conceived and designed the experiments. JH, HDB, and LFW performed experiments. ZRL and DP analyzed the data. ZRL wrote the article. All authors commented on the manuscript. All authors read and approved the final manuscript.

\section{Funding}

This study was funded by the Hunan Key Research and Development Programme (2020NK2046), China Agriculture Research System (CARS-16-E19), Scientific-Innovative of Hunan Agricultural Sciences and Technology (2019LS05, 2019LS06, 2019TD03, 2020CX58, 2020CX60), and Major Science and Technology Programs of Changsha (No. kq1804011). 


\section{Availability of data and materials}

The datasets generated during and/or analysed during the current study are available in the NCBI, https://submit.ncbi.nlm.nih.gov/subs/sra/SUB8184095/ overview. The associated BioProject number is PRJNA691100. The associated SRA numbers are SRR13413673-SR R13413682, respectively.

\section{Declarations}

\section{Ethics approval and consent to participate}

This article does not contain any studies with human participants or animals performed by any of the authors.

\section{Consent for publication}

Not applicable.

\section{Competing interests}

Zuren Li declares that he has no conflicts of interest. Jincai Han declares that he has no conflicts of interest. Haodong Bai declares that he has no conflicts of interest. Di Peng declares that he has no conflicts of interest. Lifeng Wang declares that he has no conflicts of interest. Lianyang Bai declares that he has no conflicts of interest.

\section{Author details}

${ }^{1}$ Hunan Provincial Key Laboratory for Biology and Control of Weeds, Hunan Academy of Agricultural Sciences, Changsha 410125, China. ${ }^{2}$ Collaborative Innovation Center for Field Weeds Control, Hunan University of Humanities, Science and Technology, Loudi 417000, Hunan, China.

Received: 12 April 2021 Accepted: 24 May 2021

Published online: 31 May 2021

\section{References}

Bahram M, Hildebrand F, Forslund SK, Anderson JL, Soudzilovskaia NA, Bodegom PM (2018) Structure and function of the global topsoil microbiome. Nature 560:7717. https://doi.org/10.1038/s41586-018-0386-6

Ballabio C, Lugato E, Fernández-Ugalde O, Orgiazzi A, Jones A, Borrelli P, Montanarella L, Panagos P (2019) Mapping LUCAS topsoil chemical properties at European scale using Gaussian process regression. Geoderma 355:113912. https://doi.org/10.1016/j.geoderma.2019.113912

Barakat RM, Al-Masri MI (2009) The effect of Trichoderma harzianum in combination with sheep manure organic amendment on soil suppressiveness to Fusarium wilt of tomato. Phytopathol Mediterr 48:385-395. https://doi. org/10.14601/Phytopathol_Mediterr-2743

Bardgett RD (2010) The biology of soil: a community and ecosystem approach. Oxford University Press, England, pp 1-256

Borowik A, Wyszkowska J, Kucharshi J, Bacmaga M, Tomkiel M (2017) Response of microorganisms and enzymes to soil contamination with a mixture of terbuthylazine, mestrione, and S-metolachlor. Environ Sci Pollut Res 24:1910-1925. https://doi.org/10.1007/s11356-016-7919-z

Carvalho FP (2017) Pesticides, environment and food safety. Food Energy Secur 6:48-60. https://doi.org/10.1002/fes3.108

Cherni A, Trabelsi D, Chebil S, Barhoumi F, Llorente I, Zribi K (2015) Effect of glyphosate on enzymatic activities, rhizobiaceae and total bacterial communities in an agricultural Tunisian soil. Water Air Soil Pollut 226:1-11. https://doi.org/10.1007/s11270-014-2263-8

Delgado CG, Vicente VB, Benito JM, Igual JM, Martin MJ, Cruz MS (2019) Influence of different agricultural management practices on soil microbial community over dissipation time of two herbicides. Sci Total Environ 646:1478-1488. https://doi.org/10.1016/j.scitotenv.2018.07.395

Dick WA, Thavamani B, Conley S, Blaisdell R, Sengupta A (2013) Prediction of $\beta$-glucosidase and $\beta$-glucosaminidase activities, soil organic $C$, and amino sugar N in reflectance spectroscopy. Soil Biol Biochem 56(9):9e104. https://doi.org/10.1016/j.soilbio.2012.04.003

Du ZK, Zhu YY, Zhu LS, Zhang J, Li B, Wang JH, Wang J, Zhang C, Cheng C (2018) Effects of the herbicide mesotrione on soil enzyme activity and microbial communities. Ecotoxicol Environ Saf 164:571-578. https://doi. org/10.1016/j.ecoenv.2018.08.075
Gomez-Sagasti MT, Epelde L, Anza M, Urra J, Alkorta I, Garbisu C (2019) The impact of nanoscale zero-valent iron particles on soil microbial communities is soil dependent. J Hazard Mater 364:591-599. https://doi. org/10.1016/j.jhazmat.2018.10.034

Guo AN, Ding LJ, Tang Z, Zhao ZQ, Duan GL (2019) Microbial response to $\mathrm{CaCO}_{3}$ application in an acid soil in southern China. J Environ Sci 79:321-329. https://doi.org/10.1016/j.jes.2018.12.007

Huang M, Tian A, Chen J, Cao F, Liu L (2020) Soil bacterial communities in three rice-based cropping systems differing in productivity. Sci Rep 10(1):9867. https://doi.org/10.1038/s41598-020-66924-8

Kumar U, Nayak KA, Shahid M, Gupta VG, Panneerselvam P, Mohanty S (2018) Continuous application of inorganic and organic fertilizers over 47 years in paddy soil alters the bacterial community structure and its influence on rice production. Agric Ecosyst Environ 262:65-75. https:// doi.org/10.1016/j.agee.2018.04.016

Kumar U, Behera S, Saha S, Das D, Guru PK, Kaviraj M (2020) Non-target effect of bispyribac sodium on soil microbial community in paddy soil. Ecotoxicol Environ Saf 189:110019. https://doi.org/10.1016/j.ecoenv. 2019.110019

Li ZR, Li DH, Zhou SF, Zhou XM, Bai LY (2018) The weeds control of a novel bioorganic fertilizer and its effects on agronomic traits of rice. Int J Agric Biol 20:507-512. https://doi.org/10.17957/IJAB/15.0509

Ling N, Zhang W, Tan S, Huang Q, Shen Q (2012) Effect of the nursery application of bioorganic fertilizer on spatial distribution of Fusarium oxysporum f. sp. niveum and its antagonistic bacterium in the rhizosphere of watermelon. Appl Microbio Biotech 59:13-19. https://doi.org/ 10.1016/j.apsoil.2012.05.001

Nguyen DB, Rose MT, Zwieten LV (2018) Effect of glyphosate and a commercial formulation on soil functionality assessed by substrate induced respiration and enzyme activity. Eur J Soil Biol 85:64-72. https://doi. org/10.1016/j.ejsobi.2018.01.004

Oca-Vasquez G, Campos FS, Vega-Baudrit JR, Mondejar RL, Odriozola I, Vera A (2020) Environmentally relevant concentrations of silver nanoparticles diminish soil microbial biomass but do not alter enzyme activities or microbial diversity. J Hazard Mater 391:122224. https://doi.org/10. 1016/j.jhazmat.2020.122224

Pearson BA, Scott RC, Carey VF (2008) Urea ammonium nitrate effects on bispyribac and penoxsulam efficacy. Weed Technol 22(4):597-601. https://doi.org/10.1614/WT-07-139.1

Stark CH, Condron LM, O'Callaghan M, Stewart A, Di HJ (2008) Differences in soil enzyme activities, microbial community structure and short-term nitrogen mineralisation resulting from farm management history and organic matter amendments. Soil Biol Biochem 40:1352-1363. https:// doi.org/10.1016/j.soilbio.2007.09.025

Sun M, Xiao TF, Ning ZP, Xiao EZ, Sun WM (2015) Microbial community analysis in rice paddy soils irrigated by acid mine drainage contaminated water. Appl Microbiol Biotech 99(6):2911-2922. https://doi.org/ 10.1007/s00253-014-6194-5

Tao JM, Meng DL, Qin C, Liu XD, Liang YL, Xiao YH (2018) Integrated network analysis reveals the importance of microbial interaction for maize growth. Appl Microbiol Biotechnol 102:3805-3818. https://doi.org/10. 1007/s00253-018-8837-4

Uddin M, Chen JW, Qiao XL, Tian R, Arafat Y, Yang XJ (2019) Bacterial community variations in paddy soils induced by application of veterinary antibiotics in plant-soil systems. Ecotoxicol Environ Saf 167:44-53. https://doi.org/10.1016/j.ecoenv.2018.09.101

Wang BZ, Zhang CX, Liu JL, Zeng XW, Li FR, Wu YC (2012) Microbial community changes along a land-use gradient of desert soil origin. Pedosphere 22(5):593-603. https://doi.org/10.1016/S1002-0160(12)60044-7

Wang W, Luo X, Chen Y, Ye X, Wang H, Cao Z (2019a) Succession of composition and function of soil bacterial communities during key rice growth stages. Front Microbiol 10:421. https://doi.org/10.3389/fmicb.2019. 00421

Wang XJ, Liu BJ, Ma J, Zhang YH, Hu TL, Zhang H (2019b) Soil aluminum oxides determine biological nitrogen fixation and diazotrophic communities across major types of paddy soils in China. Soil Biol Biochem 131:81-89. https://doi.org/10.1016/j.soilbio.2018.12.028

Wang TC, Wu Y, Li ZC, Xue S (2020) Potential impact of active substances in non-thermal discharge plasma process on microbial community structures and enzymatic activities in uncontaminated soil. J Hazard Mater 393:122489. https://doi.org/10.1016/j.jhazmat.2020.122489 
Willy DK, Muyanga M, Mbuvi J, Jayne T (2019) The effect of land use change on soil fertility parameters in densely populated areas of Kenya. Geoderma 343:254-262. https://doi.org/10.1016/j.geoderma.2019.02.033

Wu K, Yuan SF, Wang LL, Shi JX, Zhao J, Shen B (2014) Effects of bio-organic fertilizer plus soil amendment on the control of tobacco bacterial wilt and composition of soil bacterial communities. Biol Fertil Soils 50:961-971. https://doi.org/10.1007/s00374-014-0916-9

Zhu J, Peng H, Ji XH, Li CJ, Li SN (2019) Effects of reduced inorganic fertilization and rice straw recovery on soil enzyme activities and bacterial community in double-rice paddy soils. Eur J Soil Biol 94:103116. https://doi.org/ 10.1016/j.ejsobi.2019.103116
Zwetsloot MJ, Juana MU, Wickings K, Wilhelm RC, Bauerle TL (2020) Prevalent root-derived phenolics drive shifts in microbial community composition and prime decomposition in forest soil. Soil Biol Biochem 145:107797. https://doi.org/10.1016/j.soilbio.2020.107797

\section{Publisher's Note}

Springer Nature remains neutral with regard to jurisdictional claims in published maps and institutional affiliations.

\section{Submit your manuscript to a SpringerOpen ${ }^{\circ}$ journal and benefit from:}

- Convenient online submission

- Rigorous peer review

- Open access: articles freely available online

- High visibility within the field

- Retaining the copyright to your article

Submit your next manuscript at $\boldsymbol{\nabla}$ springeropen.com 